\title{
Expansión extractivista, resistencia comunitaria y 'despojo político' en Bolivia
}

\author{
Isabella M. Radhuber ${ }^{1}$ \\ Marxa Chávez León \\ Diego Andreucci \\ University of Vienna, Austria \\ Higher University of San Andrés, Bolivia \\ Erasmus University, The Netherlands
}

\begin{abstract}
Resumen
La intensificación del extractivismo en Bolivia desde 2006 y el avance hacia territorios indígenas y áreas protegidas conlleva impactos negativos a espacios de vida y formas de organización política que se encuentran en ellos. Esta transformación es ejecutada a partir de "cercamientos" que implican "despojos múltiples" por lo general violentos, sobre territorios comunitarios. Este artículo amplía los debates sobre despojo en la ecología política. Profundiza la comprensión de los procesos de desestructuración social en el contexto extractivista, proponiendo el término de 'despojo político'. El artículo expone los varios ciclos históricos de cercamientos y despojos que Bolivia ha vivido desde el período colonial. Presenta los casos principales de mega-infraestructura y extractivos en el marco de la ola extractivista ampliada desde 2006, detallando los impactos que éstos significan para áreas protegidas, territorios indígenas y comunidades campesinas. Despojos múltiples separan los ámbitos de producción y reproducción, e interrumpen la relación intrínseca de las comunidades con su entorno. Argumentamos que el despojo político es parte fundante de la fragmentación de las relaciones comunitarias, y funciona mediante la expropiación de la voz política y de los espacios de decisión y participación.
\end{abstract}

Palabras clave: extractivismo, colonialidad, desarticulación social, despojo político, América Latina

\begin{abstract}
Extractivism has intensified in Bolivia since 2006, and expanded into indigenous territories and protected areas, causing negative impacts for the life spaces and forms of political organization of the affected populations. The enclosures caused by extractivist expansion entail multiple dispossessions, usually associated with violence, in communitarian territories. This article contributes to debates about dispossession in political ecology, by deepening the comprehension of processes of social dispossession in extractivist contexts, for which we propose the term "political dispossession." It lays out the various historical cycles of enclosure and dispossession that Bolivia experienced since the colonial period, and describes the main infrastructural and extractive projects promoted in the country during the extended extractivist wave since 2006, detailing their impacts on protected

\footnotetext{
${ }^{1}$ Dr. Isabella M. Radhuber, Departmento de Ciencias Políticas, Universidad de Viena, Austria. Email: isabella.radhuber "at" gmail.com. Marxa Chávez León, Sociología, Universidad Mayor de San Andrés, La Paz, Bolivia, qoriqenti "at" gmail.com. Dr. Diego Andreucci, Instituto Internacional de Estudios Sociales (ISS), Universidad Erasmus Róterdam, Países Bajos, diego.andreucci "at" gmail.com. Deseamos agradecer a las personas de las comunidades y organizaciones sociales que compartieron sus testimonios y perspectivas con nosotros. La investigación de Isabella M. Radhuber y la redacción de este artículo fueron posibles gracias a la Beca Marie S. Curie/Erwin Schrödinger y el proyecto "Intercultural democracies: power and resource flows", financiado por el Austrian Science Fund con el número de proyecto FWF: J-3726. Agradecemos esta financiación. Agradecemos al editor y a dos personas revisoras anónimas por sus comentarios a las versiones anteriores de este manuscrito.
} 
areas, indigenous territories and peasant communities. Multiple dispossessions separate productive and reproductive areas and interrupt the intrinsic relations of communities with their environment. We argue that political dispossession is a central aspect of this fragmentation of social relations, functioning via the expropriation of the political voice and the spaces of decision-making and participation of the communities.

Keywords: extractivism, coloniality, social dispossession, political dispossession, Latin America

\section{Résumé}

L'extractivisme s'est intensifié en Bolivie depuis 2006. Il s'est étendu aux territoires autochtones et aux aires protégées, causant des impacts négatifs sur les espaces de vie et les formes d'organisation politique des populations affectées. L'expansion extractiviste a confiné un espace, conduisant à de nombreuses dépossessions sur les terres communautaires, généralement associées à la violence. Cet article contribue aux débats sur la dépossession en écologie politique, en approfondissant la compréhension des processus de dépossession sociale dans des contextes extractivistes, pour lesquels nous proposons le terme de «dépossession politique». Il expose les différents cycles historiques d'enfermement et de dépossession que la Bolivie a connus depuis la période coloniale, et décrit les principaux projets d'infrastructure et d'extraction promus dans le pays pendant la vague extractiviste étendue depuis 2006. Nous détaillons leurs impacts sur les aires protégées, les territoires autochtones et communautés paysannes. La dépossession sépare les activités productives et reproductives et interrompt les relations intrinsèques des communautés avec leur environnement. Nous soutenons que la dépossession politique est un aspect central de cette fragmentation des relations sociales, fonctionnant via l'expropriation de la voix politique et des espaces de prise de décision et de participation des communautés.

Mots clés: extractivisme, colonialité, déstructuration sociale, dépossession politique, Amérique latine

\section{Introducción}

La ruptura política que vivió Bolivia a finales de 2019, que sin duda fue causada en parte por las ambiciones golpistas de una derecha racista y autoritaria, plantea también preguntas cruciales sobre las contradicciones del modelo de desarrollo impulsado por Evo Morales y el Movimiento al Socialismo (MAS) desde el año 2006. A pesar de intentos de los movimientos indígenas-campesinos de reorientar el desarrollo del país, rompiendo con un patrón "primario-exportador", Bolivia vivió en este periodo un proceso de expansión y profundización del extractivismo sin precedentes (Andreucci y Radhuber 2017). Por un lado, la extracción de recursos, particularmente en una coyuntura inicial de precios altos de los commodities, contribuyó positivamente a las finanzas estatales, favoreciendo la estabilidad política y económica y permitiendo la implementación de programas de distribución de rentas (Farthing y Kohl 2014); por el otro, sin embargo, el avance de la frontera extractiva sobre territorios indígenas y áreas protegidas, en zonas que previamente no habían sido incluidas en los mapas de exploración y explotación de recursos, intensificó los procesos de despojo a comunidades indígenas y campesinas, amenazando sus medios de vida y generando efectos de desestructuración social y cultural (Jiménez 2015).

En los últimos años, el llamado "extractivismo" ha sido un enfoque central de la ecología política anglófona y, especialmente, latinoamericana (Svampa 2019). Dos debates son de especial relevancia para este artículo. Primero, la cuestión de la estabilización o gobernanza de la extracción frente a sus impactos socioecológicos negativos; es decir, de las estrategias adoptadas por actores estatales y empresas a varias escalas, para reducir la conflictividad y la resistencia de poblaciones afectadas por el establecimiento o ampliación de actividades extractivas y afines, como la redistribución de rentas, mecanismos de participación y consulta, uso o amenaza de violencia, y otros (Frederisksen y Himley, 2019). Segundo, investigación sobre la relación entre la extracción de recursos naturales y el despojo, que se plantea primariamente en la literatura desde la perspectiva de la "acumulación primitiva", y que documenta cómo las actividades extractivas se asocian con varias formas de separación entre comunidades y sus medios de producción y reproducción (Perreault 2013).

Poniendo en diálogo estas dos literaturas, en este artículo nos proponemos profundizar la comprensión del conjunto de mecanismos y tácticas políticas que contribuyen al despojo de las poblaciones afectadas, con el fin de viabilizar cómo los proyectos extractivos en territorios en resistencia producen desarticulación política y desestructuración comunitaria. Proponemos el término "despojo político" para referirnos a estos mecanismos y 
sus efectos. Trazaremos en tres casos emblemáticos la forma en que la ampliación de la frontera extractiva en Bolivia, particularmente en el tercer gobierno de Morales (2015-2019), estuvo asociada a la desarticulación de organizaciones indígenas y campesinas no solo a nivel nacional, sino también en los mismos territorios.

Este artículo es el resultado de un trabajo colaborativo dirigido a desmantelar las "geopolíticas de saberes" dominantes (Naylor et al. 2018; Radcliffe y Radhuber 2020). La investigación se basa en una "etnografía militante" (Valenzuela-Fuentes 2019), liderada por Marxa Chávez León, de tres procesos de contestación de la expansión extractiva en Bolivia: las disputas alrededor de la construcción de una carretera a través del Territorio Indígena y Parque Natural Isiboro-Sécure (TIPNIS); la resistencia indígena a la construcción de mega-represas en la región amazónica; y la oposición de comunidades campesinas a la expansión petrolera en la Reserva de Flora y Fauna de Tariquía. ${ }^{2}$ Las actividades de recolección de datos incluyeron la participación en asambleas y movilizaciones comunitarias; la grabación de cuatro testimonios (intervenciones públicas) brindados en eventos públicos por dirigentes y comunidades de base; y seis entrevistas en profundidad (semi-estructuradas) con activistas, dirigentes y personas de base de organizaciones indígenas y campesinas. También se han analizado 81 documentos primarios, incluyendo los pronunciamientos de organizaciones sociales, y se han revisado extensivamente artículos de prensa, informes y literatura académica de relevancia.

En la siguiente sección elaboramos los conceptos claves que guían nuestro análisis, definiendo la relación entre el extractivismo y la "acumulación primitiva", e introduciendo el concepto de "despojo político." En la sección tres explicamos cómo la estrategia de desarrollo impulsada por el gobierno de Morales supuso la expansión de proyectos de mega-infraestructura y extractivistas en áreas protegidas y territorios indígenas y campesinos, resultando en graves impactos socio-ambientales y reproduciendo dinámicas de despojo existentes en Bolivia desde la época colonial. En la sección cuatro analizamos las formas en que opera lo que denominamos despojo político, demostrando cómo la expansión del extractivismo se sostiene en un conjunto de tácticas que apuntan a desarticular políticamente y a desmovilizar procesos de resistencia comunitaria. En la sección cinco sugerimos que el despojo y las rupturas políticas que sostuvieron la expansión extractivista en los años de gobierno del MAS, podrían haber acelerado la fragmentación de su base social y la erosión de su estrategia hegemónica, contribuyendo a la crisis de octubre de 2019.

\section{Acumulación, extractivismo y 'despojo político'}

En esta sección presentamos nuestra perspectiva teórica sobre el extractivismo y el despojo, basándonos en la ecología política anglófona y latinoamericana. Ponemos en diálogo literaturas que abordan el extractivismo desde una mirada crítica postcolonial y feminista, centrada en procesos de cercamiento, con debates alrededor de la cuestión de la viabilización de los proyectos extractivos, en parte enmarcados en una interpretación crítica del concepto de "gobernanza" ambiental (Bridge y Perreault 2009).

La noción de "extractivismo" ha sido introducida en la ecología política latinoamericana para referirse a la creciente extracción de minerales, hidrocarburos y otros recursos naturales, especialmente en periferias del Sur global, pero también cada vez más en países del Norte. En su definición más básica, este término describe la extracción de grandes cantidades de materiales, en procesos intensivos o de gran escala, para la exportación (Gudynas, 2013). Algunas autoras y autores, sin embargo, asocian el extractivismo a una tendencia generalizada a orientar las estrategias de desarrollo nacional hacia la exportación primaria, una herencia colonial reforzada

\footnotetext{
${ }^{2}$ Isabella M. Radhuber impulsó y coordinó el proyecto del artículo, Marxa Chávez L. lideró la investigación empírica y el primer borrador en colaboración con Isabella; y finalmente, Diego Andreucci colaboró en la elaboración conceptual y en el proceso de las revisiones finales.

La recolección de datos ha sido llevada a cabo principalmente a través de ocho visitas de campo realizadas a las comunidades de Pampa Grande, San José, Acherales y Motoví en la Reserva de Tariquía (marzo, abril, julio, agosto y diciembre de 2017); cinco visitas a las comunidades indígenas San Lorenzo, Gundonovia, Nueva Lacea y San Pablo del TIPNIS (octubre a diciembre de 2012 y marzo de 2015), y visitas a la Subcentral Indígena del TIPNIS en la ciudad de Trinidad, Beni (2016 y 2017) incluyendo entrevistas con dirigentes de la Mancomunidad de Comunidades Indígenas de los Ríos Beni, Tuichi y Quiquibey (diciembre de 2016, julio de 2017, agosto y octubre de 2018 y marzo de 2019).
} 
por el neoliberalismo global, y mantenida por gobiernos progresistas en América Latina (Svampa 2019; Brand et al. 2016). ${ }^{3}$

El extractivismo se acompaña por múltiples formas de despojo (Navarro 2014; Bebbington 2009; Colectivo Geografía Crítica Ecuador 2019). Por un lado, es una estrategia de acumulación afín a la "acumulación primitiva", que implica apropiación de recursos naturales y desposesión de valor monetario, generalmente por parte de capitales transnacionales - en un marco de "intercambio desigual" establecido desde la época colonial - y acompañado por niveles históricamente variables de extracción de renta por parte de los estados. Por el otro lado, en línea también con la teoría de la acumulación primitiva, el extractivismo implica formas directas e indirectas de "cercamiento" (enclosures); es decir, de separación de las poblaciones afectadas de sus medios de vida, históricamente asociadas a procesos de "proletarización", pauperización (la creación de "poblaciones excedentes") y la desarticulación de modos de vida pre-existentes (De Angelis 2012; Federici 2010; Roux, 2015; Perreault 2013).

Las formas directas de separación típicamente asociadas con proyectos extractivos son los cambios en los derechos de propiedad y acceso a la tierra y otros recursos. Por ejemplo, a través de concesiones mineras (Torres 2019: 134) y derechos otorgados a las empresas extractivas sobre el uso de agua a cuesta de las poblaciones locales. Estos procesos de cercamiento por vía legal resaltan el rol clave del Estado en facilitar el acaparamiento de tierra y agua en contextos de extracción (Fernández 2019; Moreano 2019). El cercamiento puede darse también de forma indirecta. En su trabajo sobre minería en el altiplano boliviano, por ejemplo, Perreault (2013) demuestra cómo, además de estrategias legales centradas en derechos de propiedad y uso, la expansión extractiva resulta en la separación de facto de las poblaciones afectadas de sus medios de vida, a través de la acumulación de desechos tóxicos en aguas y suelos que reducen la viabilidad de economías originarias campesinas centradas en la agricultura, ganadería o pesca de subsistencia.

En general, por lo tanto, desde la investigación crítica se considera el extractivismo como un proceso violento, generador de despojo de los territorios y los cuerpos afectados (Vallejo et al. 2019), y relacionado con el acaparamiento de tierra, agua y plusvalía. Esto plantea la cuestión de cómo la extracción se hace viable y se "gobierna", a pesar de sus impactos socio-ecológicos negativos, y de la resistencia de poblaciones afectadas que resulta de ellos.

Existe mucha investigación que documenta las estrategias adoptadas por estados o empresas para prevenir o contener las respuestas sociales y comunitarias a la expansión extractiva. Estas varían del uso directo de la fuerza — es decir, la violencia militar, paramilitar o privada - a tácticas más sutiles e indirectas que, a través de la "manipulación", "persuasión" o "seducción" (Frederiksen and Himley 2019), intentan obtener el consentimiento de las poblaciones afectadas, o debilitar sus respuestas. En relación a las industrias extractivas se ha estudiado, por ejemplo, el uso estratégico de la redistribución de rentas u otros beneficios a poblaciones afectadas, por parte del Estado (Gudynas 2012) o dentro de políticas de "responsabilidad social corporativa" (Himley 2013); así como la manipulación o el uso sesgado de mecanismos de participación y consulta a comunidades (Perreault 2015; Schilling-Vacaflor 2017).

En este artículo, vinculando la cuestión de la "gobernanza de la extracción" con la investigación sobre despojo en ecología política, ponemos énfasis sobre lo que nombramos "despojo político." Con este término nos referimos a las consecuencias de intervenciones que, con el fin de viabilizar la extracción, intentan contrarrestar procesos de resistencia por partes de comunidades, produciendo su desarticulación política y la pérdida de sus capacidades de decisión y gestión. Nos basamos en parte en el trabajo de Navarro (2014: 164), que sugiere que los cercamientos de recursos naturales se acompañan a "la inherente expropiación de la capacidad de hacer y de autodeterminación política" de las poblaciones afectadas. El despojo político se puede pensar como una estrategia intencional de desarticulación de organizaciones sociales y movimientos de resistencia -empleada por actores estatales, empresas u otros grupos sociales- pero a la vez permite vincular tales intervenciones con la desarticulación de lazos comunitarios.

\footnotetext{
${ }^{3}$ En este artículo, basándonos en estas elaboraciones conceptuales, adoptamos una definición ampliada de extractivismo, que nos permita referirnos a un modo de desarrollo centrado no solo en la explotación intensiva y exportación de recursos naturales, sino también en formas de apropiación y "valorización" de los territorios a través del establecimiento de proyectos de generación energética y de infraestructura relacionada con la extracción.
} 
Por lo tanto, la noción de despojo político nos permite contribuir a investigación, dentro de la ecología política, alrededor de las estrategias que permiten la viabilización, legitimización y "regularización" (Himley 2013) de los proyectos extractivos, poniendo énfasis en los efectos de desarticulación social y política que estas estrategias tienen para las comunidades afectadas y sus organizaciones. En las próximas dos secciones del artículo presentaremos un análisis de cómo, en Bolivia, la expansión del extractivismo ha resultado en múltiples procesos de cercamiento y despojo, y de cómo el despojo político en concreto ha facilitado y ha acompañado a estos procesos.

\section{Extractivismo y despojo en Bolivia en perspectiva histórica}

En esta sección describimos la relación entre extractivismo y despojo en Bolivia, en su evolución histórica. Describimos cómo, desde la época colonial, un patrón de desarrollo "dependiente" y centrado en la explotación de recursos naturales se acompañó del despojo de poblaciones indígenas y campesinas en diversos ciclos expansivos centrados en diferentes commodities y en varias regiones del país. Estas dinámicas continúan hasta el presente. A pesar del reconocimiento de derechos indígenas y de la adopción de principios "decoloniales", el proyecto de gobierno de Evo Morales se sostuvo en la profundización y expansión de las fronteras extractivas, generando impactos negativos graves en territorios indígenas y de comunidades campesinas.

\section{La herencia colonial}

La dinámica del Estado boliviano estuvo, desde la época colonial, tejida de forma indisoluble con el pago tributario de comunidades indígenas (Barragán 2015). Durante el establecimiento del poder colonial en "tierras altas" -las regiones de Bolivia ubicadas en la Cordillera de los Andes-, se reconfiguraron las formas de organización territorial y políticas pre-existentes, y se inició una historia de cercamientos a través, centralmente, del establecimiento de "encomiendas" y posteriores divisiones territoriales, así como con la instauración de la mita (trabajo forzado) (Platt et al. 2006). En "tierras bajas", sobre todo en la Amazonía, donde había una gran diversidad cultural, la presencia colonial se tradujo desde fines del siglo XVII en la fundación de Misiones o Reducciones para "indios", supervisadas por los jesuitas, hasta la expulsión de éstos en 1767. La presencia muchas veces beligerante de comunidades que hasta ahora sostienen una forma de vida itinerante (sobre la base de la caza y la pesca) habla de la imposibilidad del Estado colonial y luego del republicano de sentar su presencia continua en la Amazonía, a excepción de intervenciones militares (Combes 2015).

La aparición de haciendas en tierras altas, las políticas de "exvinculación" -que no eran otra cosa que la violenta expropiación de tierras comunales- marcó el fin del siglo XIX e inicios del XX (Rivera Cusicanqui 1984). Por su lado, la ebullición de economías regionales, gracias al auge de la quina, goma y castaña a fines del siglo XIX e inicios del siglo XX en la región norte de la Amazonía boliviana (Fifer 1990), y la expansión de grandes propiedades ganaderas en los llanos de mojos y cruceños (en el noreste y este del país), marcaron la ocupación de lo que había sido territorio indígena. Dicha ocupación acompañaba a la explotación de mano de obra de las comunidades a través de capturas y "enganches" forzosos para alimentar el "sistema de barracas" (centros de extracción gomera), así como el establecimiento de "comunidades cautivas" guaraní, que hasta el 2008 habían permanecido en condiciones de esclavitud y semi-esclavitud dentro de las haciendas en la región de El Chaco (CIDH 2009). Todo esto marcó una dinámica de cercamiento y de despojo de las comunidades indígenas.

Luego de la Revolución Nacional de 1952, fueron abolidas las relaciones de servidumbre, y la actividad primario-exportadora de minerales en tierras altas se convirtió en la forma dominante de la economía y políticas estatales. Se estableció así un capitalismo de Estado, que disponía de la renta obtenida por la extracción minera para el impulso de la reproducción ampliada del capital (Tapia 2016). Esto supuso la inversión de grandes cantidades de recursos para el desarrollo de la agroindustria en el país. El Estado post revolución de 1952 eliminó el régimen hacendal en zonas del altiplano. Una intensa agitación contra ello se había dado desde por lo menos 10 años antes (Gotkowitz 2012), estableciendo como forma general de propiedad las parcelas familiares campesinas, con una fuerte presencia del sindicato campesino como figura central de organización. 
El panorama en tierras bajas, por el contrario, derivó en la aparición de latifundios, el despegue y crecimiento de un sector agroindustrial (sobre todo en Santa Cruz) y la ocupación de territorios indígenas que el Estado consideraba vacíos. La ocupación se daba mediante planes de "colonización", lo cual significa un cercamiento reactualizado de territorios de comunidades indígenas, que tuvieron que buscar otros lugares de asentamiento o desaparecer al integrarse de manera sometida a los proyectos de modernización económica y social del Estado.

\section{Del neoliberalismo al "Proceso de Cambio"}

A lo largo de la segunda mitad del siglo XX, las políticas de diferentes gobiernos en tierras bajas favorecieron la expansión de haciendas ganaderas y regímenes locales de patronazgo. Durante la época neoliberal (1985-2005), el Estado reconoció, producto de la presión del movimiento indígena, las Tierras Comunitarias de Origen (TCOs) (Fundación Tierra 2010), pero al mismo tiempo impulsó el gran crecimiento de la agroindustria soyera. Si el Estado reconoció los convenios internacionales -como la Convención 169 de la Organización Internacional del Trabajo (1989) - y llevó adelante la titulación de territorios indígenas, fue por la constante lucha de organizaciones indígenas. La última década del siglo XX fue clave en la organización del movimiento indígena latinoamericano y boliviano y para la articulación de un proyecto político intercultural y plurinacional (Postero 2009). En 2004, en parte como resultado de un intenso ciclo de luchas que marcó el fin de la hegemonía de gobiernos neoliberales (Gutiérrez Aguilar 2008), se aliaron diversas organizaciones sociales de tierras altas y tierras bajas, bajo el término del "Pacto de Unidad" indígena-campesino.

Desde la década de los 90, luego de la decaída de la minería estatal, la extracción de hidrocarburos pasó a ser el eje de obtención de recursos. En estos últimos quince años, el sector de hidrocarburos y energía ha sido definido por las principales políticas nacionales como "sector estratégico" (Radhuber 2010). Sin embargo, paradójicamente, la expansión y consolidación estatal -aún con el consiguiente proceso de ciudadanización y el reconocimiento de derechos políticos- han implicado la continuidad de las políticas de cercamiento a pueblos indígenas, sobre todo de tierras bajas.

El llamado "Proceso de Cambio" -el ciclo político que se inició en 2006 con la elección presidencial de Evo Morales y su partido, el Movimiento Al Socialismo (MAS)- representó un quiebre en la composición social del Estado. El gobierno del MAS inició su primer año de gobierno retomando, en sus propias claves, una de las demandas populares-indígenas centrales de todo el ciclo de luchas del 2000 al 2005: la nacionalización de los hidrocarburos. Otras transformaciones profundas del Estado, y de su relación con la diversidad cultural y social del país, se habían pensado y discutido a nivel nacional a través de la realización, desde 2006, de la Asamblea Constituyente, como el momento de asumir un proceso de descolonización (Schavelzon 2012). Sin embargo, las medidas que el gobierno asumió, sobre todo en referencia a la política sobre hidrocarburos desde el 2007, conllevaron la apertura de otro ciclo de expansión y profundización del extractivismo y del despojo, focalizado en la Amazonía y otras regiones que no habían vivido hasta los últimos años la apertura territorial a empresas privadas y estatales.

Bajo esta configuración política, el Estado se sostuvo a partir de la denominada "renta petrolera" y desarrolló una ola homogeneizadora y modernizante, amenazando con la desaparición de comunidades indígenas y la ruptura de ecosistemas locales y regionales, como es la Amazonía.

El último ciclo de cercamiento y despojo de comunidades indígenas se estableció a través de una serie de proyectos que emergieron con fuerza desde 2011. El conflicto alrededor del proyecto carretero Villa TunariSan Ignacio de Mojos, cuyo tramo II pasaría por el medio de la zona de estricta protección del Territorio Indígena y Parque Nacional Isiboro Sécure (TIPNIS), se convirtió en un caso paradigmático que reveló el carácter contradictorio de la política del gobierno del MAS. El conflicto del TIPNIS fue el punto de quiebre de las dos organizaciones indígenas de tierras bajas y tierras altas más importantes a nivel nacional -la Confederación Indígena del Oriente Boliviano (CIDOB), y el Concejo Nacional de Ayllus y Markas del Qullasuyu (CONAMAQ)- con el gobierno nacional (Chávez 2016).

\section{Profundización del extractivismo en el tercer gobierno del MAS}

En el tercer mandato de gobierno del MAS (2015-2019), alrededor de los beneficios por los impuestos a hidrocarburos, se afianzó un modelo económico basado en las actividades extractivas y de construcción de 
mega infraestructuras, delineando por lo menos cinco grandes e importantes frentes de avance de la frontera extractivista: (1) la ampliación y profundización de las actividades exploratorias y de explotación hidrocarburífera dentro de territorios indígenas y áreas protegidas; (2) la construcción de megaproyectos viales, como el que cruza el TIPNIS; (3) proyectos de exploración y explotación minera que privilegian a actores privados (4); la puesta en marcha de seis proyectos mega-hidroeléctricos; y (5) diversas leyes que favorecen la expansión de la agroindustria y el agronegocio.

La flexibilización de normativas ambientales y la apertura legal de las áreas protegidas fueron la tónica de esta fase de expansión extractivista. En el año 2015, el gobierno dio un golpe de timón a las políticas de exploración y explotación de hidrocarburos (entrevista a Jorge Campanini, 17 marzo de 2017). A través de tres Decretos Supremos consecutivos (2298, 2366 y 2400), se permitió el ingreso de actividades petroleras en áreas protegidas -que en muchos casos están superpuestas a territorios indígenas- flexibilizando las medidas de protección ambiental incluidas, entre otras, en la Ley de Hidrocarburos de 2005. También se flexibilizaron derechos reconocidos de los pueblos indígenas, como el de la Consulta Previa. ${ }^{4}$

El crecimiento sin precedentes de la frontera petrolera (ANF 2015), las medidas agrarias que favorecen la deforestación y a la gran agroindustria soyera, así como la ejecución de las primeras fases de construcción de mega-represas como la de El Bala-Chepete y Rositas en tierras bajas, iniciaron un tiempo de confrontación de las comunidades indígenas con el Estado y con actores sociales afines al gobierno, como los "colonos" campesinos, que son afines al gobierno y se han enfrentado ya con pueblos indígenas (Página Siete 2015). Los efectos de estos proyectos hacia nuevos "territorios de sacrificio" (Jiménez 2015) implican agudización de la contaminación de suelos y vertientes de agua, "fractura ecológica" y amenaza de desaparición del territorio de comunidades indígenas.

La tabla 1 sintetiza los principales proyectos que están dentro de áreas protegidas y territorios indígenas, impulsados por el gobierno del MAS en esta coyuntura. ${ }^{5}$

\section{Defensa de los territorios y despojo político}

En agosto de 2011 partía rumbo a la ciudad de La Paz, sede de gobierno, la Octava Marcha Indígena, que protestaba contra la construcción de la carretera del TIPNIS sin consulta previa a comunidades indígenas. La represión estatal de la marcha, atacada por la policía en la localidad de Chaparina (Beni), marcó la ruptura de las dos organizaciones indígenas a nivel nacional -la CIDOB y el CONAMAQ- con el gobierno. A partir de este punto de inflexión, se iniciaron sistemáticas acciones gubernamentales para imponer los proyectos de mega-infraestructura y extractivistas en territorios indígenas, que se instituyeron también como procesos que denominamos de "despojo político."

Esto implicó una crisis dentro de los mundos comunitarios e indígenas que se extendió desde las organizaciones nacionales hasta las estructuras comunitarias y de base. Por lo cual, en nuestro análisis del despojo político, nos referimos no únicamente a un proceso de destrucción de las organizaciones indígenas nacionales a través de estrategias como el paralelismo y la toma de dirigencias, ya documentada por otras investigaciones (Andreucci y Radhuber 2017); sino también a la profundización de la desestructuración política a nivel comunitario. Frente a esta desarticulación política, las comunidades volvieron a pelear, en peores condiciones, para defender el núcleo de la existencia comunitaria, el territorio, así como sus formas de relacionamiento político intercomunitario y su convivencia con sus entornos ecosistémicos.

\footnotetext{
${ }^{4}$ La Consulta Previa, incluida en la Ley de Hidrocarburos de 2005, adopta la obligación de obtener el "consentimiento libre, previo e informado" de pueblos indígenas para realizar obras o actuar medidas legislativas que les afecten, establecido por la Convención 169 de la Organización Internacional del Trabajo (OIT 1989).

${ }^{5}$ Si bien existen otros casos de despojo comunitario relacionados directa o indirectamente con la expansión de dichos proyectos, que no figuran en este recuento, los datos permiten establecer las dimensiones del avance de la frontera extractiva, que tiene caracteres inéditos y consecuencias graves, previstas por los estudios de impacto ambiental existentes. Es preciso anotar que a estos proyectos de mega-infraestructura y extractivistas de gran escala se suman otros que, a pesar de ser más pequeños y localizados, o son parte de mega-proyectos o, aunque no lo sean, son producto de negociaciones con capital transnacional (sobretodo chino) y de una lógica de avance, ocupación, cerco y despojo.
} 


\begin{tabular}{|c|c|c|c|}
\hline $\begin{array}{l}\text { Sector o } \\
\text { tipo de } \\
\text { proyecto } \\
\end{array}$ & $\begin{array}{l}\text { Nombre del } \\
\text { proyecto o medida }\end{array}$ & $\begin{array}{l}\text { Principal empresa } \\
\text { involucrada } 0 \\
\text { beneficiada }\end{array}$ & Zonas y poblaciones afectadas \\
\hline \multirow[t]{6}{*}{$\begin{array}{l}\text { Hidro- } \\
\text { eléctrico }\end{array}$} & El Bala-Chepete & $\begin{array}{l}\text { Estudios preliminares } \\
\text { finales: Geodata (Italia) }\end{array}$ & $\begin{array}{l}\text { Parque Nacional Madidi (La Paz) } \\
\text { Reserva de la biosfera y Tierra Comunitaria de } \\
\text { Origen Pilón Lajas (La Paz) } \\
\text { Comunidades indígenas de Rurrenabaque (Beni) } \\
\text { Comunidades campesinas en La Paz }\end{array}$ \\
\hline & Rositas & $\begin{array}{l}\text { Estudios preliminares: } \\
\text { Eptisa (España) }\end{array}$ & $\begin{array}{l}\text { Poblaciones de Vallegrande y Cabezas (Santa Cruz) } \\
\text { Comunidades Guaraní (Santa Cruz) }\end{array}$ \\
\hline & Cuenca Río Madera & En fase de proyecto & Bosques de la Amazonía (Pando y Beni) \\
\hline & Cachuela Esperanza & $\begin{array}{l}\text { Estudios preliminares: } \\
\text { Tecsult (Canadá) }\end{array}$ & Provincia Vaca Díez (Beni) \\
\hline & Cambarí & En fase de proyecto & $\begin{array}{l}\text { Zona núcleo y comunidades de Reserva Nacional de } \\
\text { Flora y Fauna Tariquía (Tarija) }\end{array}$ \\
\hline & Ivirizú & Sinohidro (China) & $\begin{array}{l}\text { Zona boscosa de alta biodiversidad en el Parque } \\
\text { Nacional Carrasco (Cochabamba) }\end{array}$ \\
\hline Vial & $\begin{array}{l}\text { Carretera Villa Tunari } \\
-\quad \text { San Ignacio de } \\
\text { Mojos }\end{array}$ & $\begin{array}{l}\text { Construcción carretera y de } \\
\text { puentes en el Tramo II que } \\
\text { atraviesa por el medio el } \\
\text { TIPNIS: AMVI y Sergut } \\
\text { (Bolivia) }\end{array}$ & Zona núcleo del TIPNIS (Beni y Cochabamba) \\
\hline \multirow[t]{5}{*}{$\begin{array}{l}\text { Hidro- } \\
\text { carburífero }\end{array}$} & San Telmo-Astillero & Petrobras (Brasil) & $\begin{array}{l}\text { Reserva Nacional de Flora y Fauna Tariquía RNFFT } \\
\text { (Tarija) } \\
\text { Áreas destinadas a la producción agrícola y al } \\
\text { pastoreo (Tarija) }\end{array}$ \\
\hline & $\begin{array}{l}\text { Madre de Dios y } \\
\text { Nueva Esperanza }\end{array}$ & $\begin{array}{l}\text { Sinopec (China); } \\
\text { asociación accidental BGP } \\
\text { (China) }\end{array}$ & $\begin{array}{l}\text { Amazonía norte, cuenca del Madre de Dios (Pando } \\
\text { y Beni) }\end{array}$ \\
\hline & $\begin{array}{l}\text { Aguaragüe Centro y } \\
\text { Los Monos }\end{array}$ & YPFB Chaco (Bolivia) & $\begin{array}{l}\text { Parque Nacional y Área Natural de Manejo } \\
\text { Integrado Aguaragüe, (Tarija) }\end{array}$ \\
\hline & Azero & Total (Francia) & $\begin{array}{l}\text { Parque Nacional y Área Natural de Manejo } \\
\text { Integrado Iñao (Chuquisaca) }\end{array}$ \\
\hline & $\begin{array}{l}\text { Exploración de gases } \\
\text { no convencionales } \\
\text { (fracking) }\end{array}$ & Cancabria (Canadá) & $\begin{array}{l}\text { Zona de Miraflores y Macharetí, donde viven } \\
\text { comunidades guaraní. (Chuquisaca) }\end{array}$ \\
\hline \multirow[t]{2}{*}{ Minero } & $\begin{array}{lr}\text { San Cristóbal } & - \\
\text { ampliación } & \text { de } \\
\text { concesiones } & \\
\end{array}$ & Sumitomo (Japón) & Comunidades aledañas al proyecto (Potosí). \\
\hline & Mallku Quta & $\begin{array}{l}\text { South American Silver } \\
\text { (Canadá, expulsada) }\end{array}$ & $\begin{array}{l}\text { Cinco lagunas donde las comunidades se proveen de } \\
\text { agua, y que también es hogar de cóndores (Potosí) }\end{array}$ \\
\hline \multirow[t]{2}{*}{ Agrícola } & $\begin{array}{l}\text { Resolución Nro } 0530 \\
\text { del Instituto Nacional } \\
\text { de Reforma Agraria, } \\
\text { INRA (2010) }\end{array}$ & & $\begin{array}{l}\text { Bosque de Tsimanes (Beni); la resolución del INRA } \\
\text { declaró como tierras fiscales antiguas concesiones } \\
\text { forestales, cuando, deberían figurar como parte del } \\
\text { territorio indígena Tsimane y no como propiedad del } \\
\text { estado boliviano. }\end{array}$ \\
\hline & $\begin{array}{l}\text { Ley del Etanol (11 de } \\
\text { septiembre de 2018) }\end{array}$ & & $\begin{array}{l}\text { La Amazonía y la Chiquitanía serán afectadas por la } \\
\text { deforestación que se precisa para la siembra de caña } \\
\text { y otros productos que serán destinados a la } \\
\text { producción de etanol. }\end{array}$ \\
\hline
\end{tabular}

Tabla 1: Nuevos proyectos o medidas que afectan territorios indígenas y reservas naturales en Bolivia (2015-2019). Elaboración propia. 
Al fin de ilustrar procesos de despojo político, en esta sección presentamos el análisis de tres casos de conflicto entre los más significativos en el contexto boliviano actual: dos protagonizados por pueblos indígenas y uno por comunidades campesinas. Estos casos muestran, por un lado, la resistencia y lucha sostenida desde las comunidades afectadas en defensa de sus territorios y medios de vida; y, por otro, los procesos de división y desestructuración comunitaria impulsados por actores estatales y afines, al fin de favorecer proyectos extractivos y de mega infraestructura.

\section{El TIPNIS y la división comunitaria}

Luego de la Octava Marcha Indígena, las autoridades del Estado iniciaron un proceso de intromisión y división de las estructuras orgánicas indígenas, así como de las comunidades de base, logrando la fractura de la organización indígena del TIPNIS y de la CIDOB a nivel nacional (Fabricant y Postero 2015). El gobierno desarrolló tres estrategias para debilitar la resistencia indígena a la carretera: 1) acudir directamente a las comunidades de base con ofrecimientos de "proyectos de desarrollo" y la entrega de "regalos" (pelotas, playeras, antenas de telefonía celular y alimentos, entre otros); 2) impulsar la creación de dirigencias paralelas a las orgánicamente elegidas, así como generar pugnas y enfrentamientos con otras representaciones indígenas (por ejemplo, el Consejo Indígena del Sur, CONISUR) (La Razón 2011); y 3) apelar a una serie de medidas legales para anular los logros de la Octava Marcha Indígena.

Operadores políticos y dirigentes impuestos a favor de la carretera, desde fines de 2011, negociaron con autoridades indígenas en cada comunidad las posibilidades de implementar varios proyectos, abriendo paulatinamente un espacio para la llegada del mismo presidente Evo Morales al territorio. La Subcentral Sécure en el TIPNIS, por ejemplo, fue dividida con la creación de una fracción afín al MAS, actuando como brazo operativo del gobierno dentro las comunidades. La fragmentación se ahondó el mismo 2012, cuando las comunidades indígenas tsimán del territorio decidieron aceptar la presencia estatal a través de proyectos de "desarrollo." En esta situación la dirigencia en resistencia determinó iniciar la Novena Marcha Indígena, rechazando la Ley 222 aprobada por el gobierno en febrero de 2012, la cual establecía la realización de una "Consulta Previa" en el TIPNIS.

La Novena Marcha, que se inició en abril de 2012, no tuvo el éxito de la anterior, y fue reprimida el día de su llegada a la ciudad de La Paz. Los y las marchistas decidieron trasladar la resistencia a su territorio. Por tanto, la realización de la llamada "Consulta Previa" se llevó adelante, en el TIPNIS, enfrentando una fuerte movilización de las comunidades en los ríos (que son las venas centrales del territorio indígena). Sin embargo, el gobierno insistió en la entrada de sus comisiones, llevando obsequios para las comunidades (alimentos, motores fuera de borda, paneles solares, entre los más repartidos), y en otros casos causando amedrentamientos a las comunidades y dirigentes que protagonizaron durante casi cuatro meses una lucha contra lo que denominaron "consulta póstuma" (FIDH 2012).

Con denuncias graves sobre irregularidades de los procedimientos de realización de una "consulta previa, libre e informada", ésta fue clausurada en un acto oficial del gobierno en noviembre de 2012, en el cual se la declaró como exitosa. Los informes de la Consulta que presentaron los órganos estatales dan por hecho que las comunidades aceptaron el proyecto carretero por medio del parque. Por el contrario, las comunidades y dirigencias orgánicas sostuvieron su rechazo rotundo a éste. De otro lado, en agosto de aquel año, el gobierno nacional fundó el "Cuartel Ecológico Juan Maraza" (La Razón 2012), que estaba dirigido a jóvenes del TIPNIS. El cuartel representó la forma de instauración de la presencia militar en un territorio al cual ésta no había llegado hasta ese momento, así como con el fin claro de debilitar la resistencia indígena.

En los años posteriores, el gobierno, a través de la Agencia para el Desarrollo de las Macroregiones y Zonas Fronterizas (ADEMAF), continuó sentando presencia estatal y promoviendo la agudización de la fragmentación comunitaria. En agosto de 2017, con una dirigencia indígena fracturada, a través de sesiones maratónicas en la cámara de diputados y de senadores, con la mayoría absoluta del MAS, se aprobó el proyecto de Ley 969 de Protección, Desarrollo Integral y Sustentable del TIPNIS (EJU.TV 2017). Con esto, se anuló la Ley 180 de Protección al TIPNIS (Gobierno de Bolivia 2011) y se abrió la posibilidad de construcción del proyecto carretero, y además se estableció la llegada de inversores privados al territorio indígena (Gobierno de Bolivia 2017). 
La apabullante logística estatal y su ofensiva mediática, para el acto de promulgación de esta Ley el 13 de agosto de 2017 en Trinidad, no detuvo la intervención coordinada de las autoridades indígenas orgánicas. Desde el 25 de agosto, las dirigencias orgánicas a la cabeza de la resistencia organizaron su propio Encuentro de Corregidores, impidiendo que brigadas de militares ingresasen al territorio llevando regalos al Encuentro de Corregidores convocado por el gobierno (Chaski Clandestino 2017).

Si bien la dirigencia indígena opuesta a la carretera realizó acciones internacionales en noviembre de 2017 -como la denuncia ante el Tribunal Internacional por los Derechos de la Naturaleza en Bonn, Alemaniano cesó el avance de obras camineras de los tramos I y III. Las obras estuvieron protegidas, en el sur del TIPNIS, por comunidades de productores de hoja de coca (Pagina Siete 2017c), afines al gobierno, las cuales impiden el ingreso de prensa, de comisiones legislativas de verificación (La Razón 2017b), y de la gente de las comunidades indígenas.

La situación de fragmentación de comunidades y la anulación de sus formas democráticas de decisión se agravó en esta fase. Informes de la dirigencia indígena orgánica, de investigadores y activistas que recorrieron varias comunidades del territorio indígena (Territorios en Resistencia 2017) -incluyendo a las que estarían a favor del proyecto carretero- evidencian la grave situación de éstas. Las comunidades sufrían la presión de operadores políticos del MAS, intentos de cooptación o amenazas directas. Muchos de los proyectos de desarrollo prometidos no se han cumplido hasta el momento de elaborarse este artículo.

\section{Mega-hidroeléctricas en el corazón de la Amazonía}

El ambicioso Proyecto Hidroeléctrico El Bala-Chepete, reasumido por el Estado boliviano después de 50 años de su planeamiento inicial, inundaría 771 kilómetros cuadrados de selva. El embalse que generaría se transformaría en el tercer lago más grande del país, afectando a seis territorios indígenas, con un costo inicial aproximado de US\$ 9 mil millones (Fundación Solón 2017; ANF 2018).

En julio de 2015, el gobierno boliviano junto a la Empresa Nacional de Electricidad (ENDE), realizó el contrato con la empresa italiana Geodata para la realización de un estudio de prefactibilidad de la Hidroeléctrica El Bala (Página Siete 2017b). Casi de inmediato, las comunidades afectadas y grupos de ecologistas de las ciudades declararon su oposición, por el peligro que representa para las familias indígenas asentadas de manera ancestral en el lugar, así como para dos parques nacionales de gran biodiversidad: el Parque Nacional y Área de Manejo Integrado Madidi, y el Parque Nacional Pilón Lajas (Jemio 2015). El 17 de octubre de 2016, las 17 comunidades aglutinadas en la Mancomunidad de Comunidades de los Ríos Beni, Quiquibey y Tuichi, así como otras tres comunidades indígenas, reunidas en Asamblea, decidieron rechazar de manera rotunda la construcción de la hidroeléctrica, anunciando que otorgaban un plazo de 72 horas para que Geodata abandonase la región.

El 6 de noviembre de ese mismo año, la Mancomunidad en Asamblea decidió iniciar el 9 de noviembre una vigilia permanente en el Estrecho de El Bala y así impedir el ingreso de maquinaria y equipos de la empresa Geodata y su subsidiaria Servicons. La vigilia indígena contó con la participación de decenas de comunarios de diversos pueblos indígenas que habitan la región, munidos de arcos y flechas (Chaski Clandestino 2016). El 21 de noviembre de 2016, los equipos de Servicons, anunciando que no podían trabajar sin el consentimiento de la población, abandonaron el lugar, siendo escoltados por indígenas en canoas y embarcaciones hasta la población de Rurrenabaque (departamento del Beni). Ésta fue considerada una gran victoria por los pueblos indígenas de la zona.

Después de la resistencia exitosa protagonizada por las comunidades, autoridades del Estado iniciaron el despliegue de estrategias que le permitieron dividir a las comunidades y aislar a sus dirigentes. Todo el año 2017, brigadas de ENDE y el gobierno recorrieron la gran mayoría de comunidades indígenas, incluidas las de más difícil acceso, con el objetivo de "socializar" entre estas el proyecto hidroeléctrico (La Razón 2017ª), pero a su vez prometiendo "proyectos de desarrollo" y llevando varios "regalos" para las comunidades. Como narra en entrevista el Vocero de la Coordinadora en Defensa de la Amazonía (CODA) y de la Mancomunidad de Comunidades Indígenas (25 de octubre de 2017), dichas brigadas llegaron a las comunidades del norte paceño buscando acuerdos con dirigencias y, posteriormente, con comunidades y personas individuales.

Es así que, paulatinamente, el gobierno logró obtener acuerdos oficiales rompiendo la unidad entre las organizaciones indígenas. En julio de 2017, ENDE y el Consejo Regional Tsimane Mosetenes-Pilón Lajas 
firmaron un acuerdo en el que el Estado se comprometía a canalizar en distintas instancias de gobierno solicitudes de obras de las comunidades, a cambio de que las 23 autoridades indígenas se comprometiesen a "garantizar que las actividades de ENDE se realicen al interior de la TCO [Tierra Comunitaria de Origen] Pilón Lajas, sin obstáculos." Es decir, para la realización del "proceso de información, socialización, levantamiento de datos, y realización de estudios que permitan el Estudio de Diseño Técnico de Preinversión [EDTP]" (La Patria 2016).Un acuerdo similar fue firmado por la Central Indígena de Pueblos Lecos de Apolo (CIPLA), la cual desde el 2016 se había mostrado de acuerdo con el proyecto hidroeléctrico.

En agosto de 2017, la estrategia gubernamental obtuvo un importante triunfo con un acuerdo firmado por la CPILAP (Central de Pueblos Indígenas de La Paz), donde ésta se comprometía a impulsar el proyecto hidroeléctrico El Bala-Chepete, sus trabajos de estudio final y una "socialización", a cambio del compromiso del gobierno y ENDE de realizar la "electrificación con paneles solares a las comunidades; además de gestionar requerimientos de salud y educación" (Erbol 2017). El reingreso de ENDE, así como las empresas Geodata y Servicons a la zona -luego de la resistencia triunfante contra éstas de fines del 2016-, se plasmó en julio de 2017. Según los dirigentes de la Mancomunidad, la cantidad de recursos que movilizaron ENDE, Geodata y el gobierno nacional no podía ser comparable a lo poco que ellos como representantes indígenas podían movilizar en las mismas comunidades: "lo que hace el gobierno es prácticamente una megamentira, porque va con sus Coca-Colas, muchos pollos llevando en termos a hacer cocinar a la gente, inclusivo les pagan" (Testimonio de dirigente de la comunidad Torewa, 14 de marzo de 2018).

Los efectos de los recorridos de las brigadas gubernamentales son palpables, puesto que cuatro de cinco organizaciones indígenas regionales, así como la departamental, firmaron acuerdos de entendimiento con ENDE, en términos similares. Sin embargo, las comunidades que constituyen la resistencia al proyecto hidroeléctrico se mantuvieron movilizadas, denunciando no solo los efectos devastadores que tendrían las represas, sino la manera en que el Estado debilitó las organizaciones indígenas del lugar.

Otro elemento dentro de esta descomposición de los lazos comunitarios como efecto del ingreso de mega-proyectos (no solo hidroeléctricos, sino carreteros, mineros e hidrocarburíferos) en este sector de la Amazonía es que ahora son las mismas comunidades, ante los ofrecimientos de proyectos de desarrollo, las que comienzan a discutir la posibilidad de renunciar a su calidad de Territorios Indígenas y pasar a ser propiedad privada (como testimonió Ruth Alípaz, dirigente de la Mancomunidad de Comunidades Indígenas, 17 de mayo, 2018). En el momento de la redacción de este artículo, la situación permanecía crítica para la organización de comunidades en resistencia al proyecto hidroeléctrico, puesto que Geodata, aunque con un retraso de entrega, avanzaba en la elaboración de estudios que son los pasos finales rumbo a la licitación pública internacional, que concluiría con la contratación de una empresa que ejecute obras.

\section{El Comité de Defensa de Tariquía}

Los proyectos de exploración hidrocarburífera en los bloques San Telmo y Astillero, dentro la Reserva Nacional de Flora y Fauna Tariquía (RNFFT), en el departamento de Tarija, fueron planeados por el gobierno nacional desde el año 2007, cuando estas zonas se declararon como "área de interés" para la empresa pública Yacimientos Petrolíferos Fiscales Bolivianos (YPFB). La RNFFT fue creada en 1989 con el fin de resguardar una de las zonas más importantes de recarga hídrica del departamento de Tarija (Ayala Bluske 1998), así como su biodiversidad. En la zona viven decenas de comunidades campesinas, organizadas en sindicatos campesinos por comunidad, los cuales a su vez se agrupan en "subcentrales" y "centrales" sindicales.

Las diez comunidades que viven dentro de la Reserva, en 2015, se enteraron de que Tariquía había sido incluida en las zonas de actividad hidrocarburífera, y decidieron movilizarse e investigar los efectos que estas actividades habían tenido en otras regiones del país. Como resultado de sus indagaciones iniciales, determinaron impedir el ingreso de cualquier proyecto hidrocarburífero a la reserva. Al ver que las organizaciones sindicales campesinas más grandes no representaban sus preocupaciones, las mujeres de Tariquía, junto a varios de sus compañeros, promovieron la formación del Comité de Defensa. Este convocó a una marcha denominada "Por la Dignidad de Tariquía", la cual, desde el 24 de abril, y durante cuatro días, recorrió el camino desde la Reserva Nacional hasta la ciudad de Tarija (Página Siete 2017ª , 2017d; López y Torrez 2018). 
A fines de 2016, activistas ambientales de la ciudad de Tarija narraron cómo el gobierno ingresó a la reserva regalando juguetes para los niños y panetones (bizcochos tradicionales) en la época navideña, realizando propaganda para los proyectos hidrocarburíferos (Testimonio de activistas de la ciudad de Tarija en reunión con activistas en Cochabamba, 21 de marzo de 2017). El 2017 continuó el ofrecimiento de proyectos productivos por parte del Estado. La Agencia Estatal de Vivienda ingresó a la reserva el mismo día en que partía la marcha hacia Tarija, otorgando programas de vivienda a la población de la zona. Esto fue visto por las comunidades en resistencia como una manera de disminuir la asistencia a la marcha.

Luego de concluir la movilización en la ciudad, sin respuestas por parte de los gobiernos departamental y nacional, la presión del Estado se agudizó, logrando la ruptura de las diez comunidades ${ }^{6}$ que son parte de la Subcentral Tariquía. Cuatro de ellas, las más pequeñas, comenzaron a apoyar el ingreso de las empresas petroleras a cambio de proyectos de "desarrollo", quedando las seis comunidades más grandes en la resistencia a las actividades exploratorias (Entrevista a dirigente de Subcentral Tariquía, 17 de diciembre de 2017). Después de la fractura interna de la Subcentral, las comunidades a favor de la empresa crearon el "Comité de Desarrollo", para impulsar proyectos productivos que el gobierno ofrecía en cada comunidad, y también apoyar el ingreso de la exploración de hidrocarburos (López y Torrez 2018). En este contexto, la empresa Bolpegas realizó algunos trabajos de exploración magnetotelúrica en las comunidades dentro de la reserva sin consulta de las mismas, por lo cual estas decidieron expulsarla de manera pacífica (ANF 2017).

En junio de 2017, la resistencia al ingreso de las petroleras obtuvo un triunfo importante al ganar la dirigencia de la Subcentral Tariquía (Oxígeno 2017). Sin embargo, la tensión entre la Subcentral Tariquía y el Comité de Desarrollo continuó al interior de las comunidades, provocando, por ejemplo, que actividades conjuntas que antes organizaban todas las comunidades, perdiesen fuerza y fueran organizadas solo por una parte de las mismas. También se dieron algunas rencillas, como la que ocurrió en el aniversario de Tariquía ese 21 de noviembre, cuando las autoridades sindicales de la Subcentral impidieron que reparticiones de Estado ingresaran a la reserva sin permiso y desconociendo las actividades que había planificado la Subcentral para esa fecha (Entrevista a dirigente de Subcentral Tariquía, 17 de diciembre de 2017). El hecho fue simbólicamente fuerte, puesto que es uno de los pocos lugares donde las comunidades rechazan de manera tan tajante la presencia de entidades de Estado y sus obsequios.

El carácter de la división comunitaria, hasta ese entonces, se había plasmado en la fragmentación de comunidades, su espacio de organización sindical como es la Subcentral, la ruptura intrafamiliar y las agresiones a mujeres que son parte de la resistencia (Entrevista a comunaria de Pampa Grande, Tariquía, 17 de diciembre de 2017). En 2018, con más virulencia dentro la Reserva, los ataques de las personas aliadas al gobierno contra las mujeres que lideran los cargos sindicales en todas las comunidades son un ejemplo evidente sobre cómo se despliegan mecanismos de violencia de género para la imposición de la exploración y explotación hidrocarburífera (Chávez y López 2018). Todas las mujeres que ocupan puestos sindicales o en la Asociación de Mujeres han vivido ataques verbales, amenazas y una campaña de desprestigio que apela a su condición de mujeres en el espacio de representación pública (Testimonio de mujeres brindado al Ampliado Sindical de Subcentral Tariquía, 7 de junio de 2018).

Los acuerdos con la petrolera brasilera PETROBRAS -a la cual, desde un inicio, se le habían encomendado los primeros trabajos de cuantificación de reservas- finalmente se concretaron a finales de marzo de 2018 (El País 2018), y fueron reconocidos como leyes en abril de ese año. Las comunidades de base en Tariquía no fueros informadas y mucho menos consultadas sobre estos acuerdos y leyes, y se mostraron sorprendidas y molestas por estos hechos (Página Siete 2018b). La Subcentral se movilizó entonces para denunciar la aprobación inconsulta de los contratos, realizando actividades en la ciudad de Tarija en conmemoración de un año de la Marcha en defensa de Tariquía (Quiroga 2018). El apoyo a las comunidades en resistencia, ciertamente cuestionado, proveniente de organizaciones cívicas departamentales ${ }^{7}$ y de la

\footnotetext{
${ }^{6}$ Las comunidades son Acherales, Cambarí, San José, Acheralitos, Pampa Grande, Puesto Rueda, Motoví, San Pedro, Volcán Blanco y Chillahuatas.

${ }^{7}$ La pugna entre los llamados "comités cívicos" y gobernaciones de varios departamentos en el país, entre ellos Tarija, se originó durante los primeros años de gobierno del MAS, debido a que estos entes proclamaron como proyecto político la
} 
autoridad máxima del departamento -el gobernador Adrián Oliva, opositor al gobierno nacional- derivó en la decisión temporal por parte del gobierno de suspender las inversiones en exploración hidrocarburífera en Tariquía (Página Siete 2018a). Como se vio después, esta medida era solo una estrategia para movilizar y aglutinar a comunidades a favor del ingreso de las petroleras, marcando un momento muy fuerte de la división comunitaria.

Las marchas y pronunciamientos de sindicatos campesinos que no pertenecen directamente a la reserva exigiendo que retornase la inversión petrolera, se realizaron apenas una semana después del anuncio de su suspensión, generando nuevamente un ambiente muy tenso en las comunidades, provocando además agresiones contra la dirigencia de la Subcentral Tariquía, en especial contra las mujeres dirigentes, las cuales son la base que sostiene la resistencia (Entrevista a $\square$ irigente de Subcentral Tariquía 2018). Pese a las divisiones internas, la lucha comunitaria sigue apelando a la fuerza de las mujeres y la fuerza orgánica que representa la Subcentral, entendiendo lo "orgánico" como la capacidad política colectiva de participación, discusión y decisión autónomas.

\section{Viabilizar la extracción, desarticular comunidades}

Estos tres casos ejemplifican las formas de operar del "despojo político", mostrando algunas de las tácticas empleadas por actores estatales y afines con el objetivo de favorecer el establecimiento o desarrollo de proyectos extractivos, energéticos o de infraestructura. Se trata de tácticas históricamente empleadas en contextos coloniales y en las periferias extractivas para dividir comunidades y reducir o contener su capacidad de movilización y resistencia, y consisten principalmente en la cooptación de dirigencias o sectores de las comunidades, a través de ofertas de obsequios, dinero, empleo o proyectos de desarrollo local.

Como es señalado por otras investigaciones, tales tácticas se emplean a menudo para manipular o alterar procesos de consulta o participación, con el fin de obtener legitimidad social o legal alrededor de proyectos controvertidos de gran impacto socio-ecológico, como en los casos presentados en este artículo. Estas tácticas de "manipulación", "persuasión" y "seducción" - para retomar la tipología propuesta por Frederiksen y Himley (2019)- se acompañan siempre, sin embargo, del uso o amenaza de la violencia militar, política o, como en el caso de Tariquía presentado arriba, de género.

Este tipo de intervenciones, que intentan prevenir o contener respuestas sociales de las comunidades afectadas, forman parte del modus operandi de las empresas extractivas que operan en las periferias globales. Al mismo tiempo, lo que distingue el caso de Bolivia en los años de gobierno del MAS es el mayor protagonismo cobrado por el mismo Estado en dirigir e implementar esta estrategia de desarticulación política, bajo el imperativo de proteger sectores económicos -como el extractivo y de la energía- considerados "estratégicos."

Por un lado, como señalamos en el caso del TIPNIS, se da un aumento de la presencia de actores estatales y de fuerzas militares en territorios indígenas históricamente distantes de los centros administrativos y de control gubernamental. El aumento de la presencia estatal en estos territorios no es de por sí algo negativo; el mismo gobierno del MAS la reivindica como una forma de afirmar la soberanía estatal en regiones, como la amazónica, históricamente controladas por la "élite hacendal-empresarial" y "gobiernos extranjeros" (García Linera 2012: 30). Sin embargo, el uso de la institucionalidad estatal para reducir la capacidad de autodefensa de comunidades -y así viabilizar proyectos que favorecen primariamente a capitales transnacionales- es políticamente contradictorio, particularmente en vista de sus graves consecuencias para las poblaciones locales, como los pueblos indígenas. ${ }^{8}$

\footnotetext{
"autonomía departamental" como estrategia para afianzarse regionalmente como élites políticas y económicas, frente al estado central. El conflicto el año 2008, llegó a graves enfrentamientos entre grupos de choque de los comités y gobernaciones frente a grupos de base que apoyaban la gestión del Movimiento al Socialismo.

${ }^{8}$ Es además, en parte, una consecuencia paradójica de las demandas de las mismas organizaciones indígenas que, en la coyuntura de luchas sociales de los años 2000-2005 (entre la crisis de hegemonía del neoliberalismo y la llegada al poder del MAS), reivindicaron una mayor presencia estatal para tener más capacidad de proteger su territorio frente a las incursiones de grandes empresas transnacionales, sobre todo petroleras (como en el caso de provisiones sobre consulta y monitoreo ambiental indígena en la Ley de Hidrocarburos de 2005).
} 
Por el otro lado -en parte por su origen en los sindicatos campesinos-cocaleros, pero también por el carácter clientelar y redistributivo de su estrategia hegemónica (Tapia 2014)- el gobierno del MAS tuvo una capacidad mucho mayor que la de gobiernos anteriores de movilizar actores sociales en los territorios; por ejemplo, para enfrentarse con actores indígenas u organizaciones políticas "orgánicas" de las comunidades, o limitar de otras formas sus movilizaciones en contra de proyectos extractivos. Esto contribuyó a que, en la coyuntura analizada en este artículo, el Estado pudiera desarticular políticamente la resistencia comunitaria al extractivismo de forma mucho más efectiva.

Estos ejemplos nos permiten ilustrar más claramente los procesos que hemos denominado de "despojo político." En los casos analizados, vemos como las intervenciones estatales y de otros actores tienen como consecuencia inmediata la desarticulación de formas de organización política autónoma (u "orgánica") de las comunidades indígenas y campesinas de base, debilitando su capacidad de resistencia a proyectos extractivos o infraestructurales que afectan sus territorios y medios de vida. Vemos también como esto se acompaña a la descomposición de lazos comunitarios, reforzando el efecto de desagregación cultural y social típicamente asociado a los procesos de cercamiento y a la "acumulación primitiva" (Perreault, 2013).

No es nuestra intención argumentar que, anteriormente a estas intervenciones de desarticulación política, existía en los territorios considerados en este artículo una situación de harmonía intracomunitaria y de unidad organizativa y política. Sin embargo, en los tres casos presentados arriba, queda claro que tales intervenciones pretenden precisamente frustrar intentos -en buena medida exitosos- por parte de las comunidades, de organizar procesos de lucha territorial. En el caso más paradigmático, el de las organizaciones indígenas del TIPNIS, estas luchas llegan a socavar el núcleo ambientalista e indigenista de lo que fue una amplia alianza bajo el gobierno MAS. Pero también en los casos del Proyecto Hidroeléctrico El Bala-Chepete y de Tariquía, se entiende claramente como las intervenciones estatales responden a la necesidad de desarticular procesos de movilización que están consiguiendo liderar procesos de resistencia a la entrada sin "consentimiento previo" de proyectos extractivos o de mega-infraestructura, y que tienen potencial de convertirse en focos más amplios de crítica y disenso político.

La perspectiva del despojo político, en resumen, nos permite contribuir a la literatura de ecología política principalmente de dos maneras. Primero, nos proporciona una herramienta conceptual más precisa, dentro del marco más amplio de la "acumulación primitiva" o "por desposesión/despojo", que permita enfocar específicamente la pérdida de capacidad de articulación y movilización política de las comunidades afectadas, que a la vez acompaña y facilita otras formas de cercamiento y despojo asociados con la expansión extractivista. Segundo, este concepto aporta también a la investigación más especializada sobre formas de viabilización del extractivismo, definiendo un conjunto de prácticas estatales y empresariales -en parte ya estudiadas individualmente- que apuntan a fomentar la división comunitaria y política y de esta forma reducir las amenazas a la continuidad de actividades extractivas.

En defender formas autónomas de organización comunitaria, y el ejercicio de derechos a la consulta y participación de pueblos indígenas y campesinos, no entramos en debates de gran complejidad sobre la capacidad real de países "periféricos", como Bolivia, al impulsar cambios estructurales en el patrón de desarrollo, revertiendo la "división colonial del trabajo" entre economías industriales y primario-exportadoras. Muchos observadores internacionales -así como muchos actores sociales, incluso de clases "subalternas", en Bolivia- han defendido, desde una mirada pragmática, el modelo "neo-extractivista" (o de "extractivismo con redistribución") implementado por el gobierno del MAS como la mejor opción posible en un contexto de presiones geopolíticas y político-económicas globales, para mejorar las condiciones materiales de amplios sectores de la población del país.

Sin embargo, es importante también visibilizar cómo estas políticas tienen un coste socio-ecológico muy alto, asumido en su mayoría por comunidades indígenas y campesinas en territorios de extracción, y cuyas consecuencias son agravadas por las divisiones sociales y políticas resultantes de la intervención estatal. Es crucial defender el respeto de la capacidad decisional, política y organizativa de las comunidades indígenas y campesinas afectadas; su derecho a rechazar y vetar proyectos extractivos-infraestructurales o a negociar, desde una posición de autonomía y libres de represión y amenazas, la obtención de beneficios derivados de estos proyectos y la minimización de sus impactos socio-ambientales. 
La participación de organizaciones sociales en instancias del Estado fue uno de los proyectos sostenidos por el MAS y todos los sectores que apoyaron a este partido en diciembre de 2005. Sin embargo, catorce años después, resulta claro como la continuidad de prácticas y visiones coloniales para la apropiación y valorización de los territorios reproducen, bajo nuevas condiciones, formas de despojo para las poblaciones afectadas. La expansión del extractivismo fue cuestionada y frenada temporalmente por procesos de lucha complejos y diversos; rearticulaciones sociales a partir de claves como el cuidado y la defensa de los espacios comunes y de otras especies no humanas; y un veto a las formas de cercamiento y ocupación de lo colectivo en favor de lo privado.

Las dinámicas de "despojo político" impulsadas en el periodo del gobierno MAS cercenaron organizaciones indígenas a nivel nacional, ocupando físicamente sus sedes, desconociendo a sus dirigencias orgánicas, dividiéndolas y cooptándolas a partir de figuras dirigenciales afines al partido de gobierno, irrumpiendo y fragmentando las estructuras más locales y en las relaciones inter- e intrafamiliares y comunitarias. Estas rupturas políticas contribuyeron a erosionar la estrategia hegemónica del MAS -en parte fragmentando su propia base social, y en parte alienando el apoyo político-ideológico de las clases medias progresistas- lo que contribuyó a la crisis política de octubre de 2019.

\section{Conclusiones}

En este artículo, argumentamos que la expansión del extractivismo en Bolivia en los últimos años ha sido asociada con nuevos cercamientos de territorios indígenas y campesinos, legalizados a través de diferentes normativas que flexibilizan leyes ambientales y sociales para favorecer la llegada de grandes empresas petroleras, mineras, hidroeléctricas, y agrícolas. Tal expansión fue acompañada por "despojo político" -la ruptura de la capacidad de organización política autónoma de las comunidades, resultado de estrategias neocoloniales de división y amedrentamiento- para viabilizar proyectos extractivos y de mega-infraestructura en territorios indígenas-campesinos. Demostramos cómo esta ampliación -y los procesos de cercamiento a territorios indígenas y áreas protegidas que conlleva- ha generado desintegración comunitaria, amenazas de desaparición de pueblos indígenas y, con ello, la conversión de dichos territorios de gestión comunitaria en propiedad privada y en espacios para la reproducción y expansión de capitales empresariales transnacionales. Esto ha implicado niveles importantes de destrucción socio-ambiental, suponiendo un despojo no solo a pueblos indígenas, sino de una escala interregional, panamazónica, que tiene un efecto en las ciudades y en la crisis climática global. Trazar y conceptualizar el despojo político aspira a entender mejor cómo se viabiliza y legitima la expansión del extractivismo en los territorios, frente a su violencia y destructividad.

\section{Bibliografía}

Andreucci, D. and I.M. Radhuber. 2017. Limits to "counter-neoliberal" reform: mining expansion and the marginalisation of post-extractivist forces in Evo Morales's Bolivia. Geoforum 84: 280-291.

ANF (Agencia de Noticias Fides). 2015. Nuevo decreto de Evo amplía la frontera petrolera a casi 32 millones de hectáreas (15.11.2015) [accessed January 6 2018]. http://www.noticiasfides.com/economia/nuevodecreto-de-evo-amplia-la-frontera-petrolera-a-casi-32-millones-de-hectareas-359377-359327

ANF (Agencia de Noticias Fides). 2017. Campesinos en emergencia advierten con desalojar a empresa $\begin{array}{llllll}\text { Bolpegas de Tariquía (17.08.2017) } \quad \text { [accessed January } & 7 & 2018] .\end{array}$ https://www.noticiasfides.com/economia/campesinos-en-emergencia-advierten-con-desalojar-aempresa-bolpegas-de-tariquia-380879

ANF (Agencia de Noticias Fides). 2018. Chepete Bala: ministro advierte que estudio a diseño final será diferente al de prefactibilidad (10.05.2018) [accessed January 6 2018].https://www.noticiasfides.com/economia/chepete-bala-ministro-advierte-que-estudio-a-disenofinal-puede-ser-muy-diferente-al-de-prefactibilidad-387910

Ayala Bluske, R (ed.). 1998. Áreas protegidas del departamento de Tarija. Protección del Medio Ambiente Tarija (PROMETA) - Programa de Conservación y Desarrollo (IYA) - Grupo de Desarrollo Rural Grupo (DRU). Tarija, Bolivia: W Producciones. 
Barragán, R. 2015. El Estado pactante: pensando en la fortaleza de la sociedad organizada. Tinkazos 18(37): 101-112.

Bebbington, A.J. 2009. Latin America: contesting extraction, producing geographies. Singapore Journal of Tropical Geography 30(1): 7-12.

Brand, U., K. Dietz and M. Lang. 2016. Neo-extractivism in Latin America-one side of a new phase of global capitalist dynamics. Ciencia Política 11(21): 125-159.

Bridge, G. and T. Perreault. 2009. Environmental governance. In Castree, N., D. Demeritt, D.L. Liverman and B. Rhoads (eds.). A companion to environmental geography. Malden, MA: Wiley.

Chaski Clandestino. 2016. Se instala vigilia de resistencia. No-a-las-hidroelectricas en El Bala-y-Chepete (12 Nov. 2016) [accessed January 6 2018]. https://chaskiclandestino.wordpress.com/2016/11/12/se-instalavigilia-de-resistencia-no-a-las-hidroelectricas-en-el-bala-y-chepete

Chaski Clandestino. 2017. Militarizacion, hostigamiento y la obstinada lucha por el territorio y la dignidad en $\begin{array}{lllllll}\text { el Tipnis (6 } & \text { Sept. } & \text { 2017) } & \text { [accessed January } 618 \text {. }\end{array}$ https://chaskiclandestino.wordpress.com/2017/09/06/militarizacion-hostigamiento-y-la-obstinadalucha-por-el-territorio-y-la-dignidad-en-el-tipnis/

Chávez León, M. 2016. La difícil relación de lo comunitario indígena y el proyecto 'campesino-estatal' en Bolivia (2009-2014). Descomposiciones y recomposiciones. In Börries, N., G. Valencia and S. Salazar (eds.). Pensando Bolivia desde México. Estado, movimientos, territorios y representaciones. México, Distrito Federal: Posgrado en Estudios Latinoamericanos de la Universidad Nacional Autónoma de México; La Paz: Posgrado en Ciencias del Desarrollo de la Universidad Mayor de San Andrés.

Chávez, M. and C. López. 2018. Women rebel in Tariquía. NACLA Report on the Americas 50(4): 408-410.

CIDH (Comisión Interamericana de Derechos Humanos). 2009. Comunidades cautivas: situación del pueblo indígena guaraní y formas contemporáneas de esclavitud en el Chaco de Bolivia. La Paz: CIDH.

Colectivo Geografía Crítica Ecuador. 2019. Geografía crítica para detener el despojo de los territorios. Quito: Abya Yala.

Combes, I. 2015. De la una y otra banda del río Paraguay. Historia y etnografía de los itatines (siglos XVI. XVIII). Cochabamba: FTSP.

De Angelis, M. 2012. Marx y la acumulación primitiva. El carácter continuo de los "cercamientos" capitalistas. Theomai 26 (Argentina): 16-35.

EJU.TV. 2017. Evo promulga ley que quita intangibilidad al Tipnis; indígenas "opositores" marginados del festejo (13 Aug. 2017) [accessed January 6 2018]. http://eju.tv/2017/08/evo-promulga-ley-que-quitaintangibilidad-al-tipnis-indigenas-opositores-marginados-del-festejo/

El País. 2018. Senado sanciona contratos petroleros para exploración y explotación en San Telmo y Astillero (5 April 2018) [accessed January 6 2018]. https://elpais.bo/senado-sanciona-contratos-petroleros-paraexploracion-y-explotacion-en-san-telmo-yastillero/?fbclid=IwAR2AcVBP2dTJ4Z7utrWSylnZxOKP6jPAq0AELJc_XVqlqck-Qy1QQOZu1pA

Erbol. 2017. Cpilap y Ende firman acuerdo para diseño El Bala y Chepete (11. Aug. 2017) [accessed January 6 2018].

https://erbol.com.bo/noticia/economia/11082017/cpilap_y_ende_firman_acuerdo_para_diseno_el_bala _y_chepete

Fabricant, N. and N. Postero. 2015. Sacrificing indigenous bodies and lands: the political-economic history of lowland Bolivia in light of the recent TIPNIS debate. The Journal of Latin American and Caribbean Anthropology 20(3): 452-474.

Farthing, L. and B. Kohl. 2014. Evo's Bolivia: continuity and change. Austin: University of Texas Press.

Federici, S. 2010. Calibán y la bruja. Argentina: Tinta Limón Ediciones.

Fernández, A., M. Moreano, B. Gutiérrez, S. Cando, N. Romero Salgado, M. Bayón Jiménez, D. Murillo and A. Molina. 2019. Violencia estatal, colonialismo interno y despojo: la implantación del proyecto minero 
Panantza-San Carlo. In Colectivo Geografía Crítica Ecuador (ed.). Geografía crítica para detener el despojo de los territorios. Quito: Abya Yala.

FIDH (Federación Internacional de los Derechos Humanos). 2012. Verificación de la consulta en el TIPNIS [accessed January 5 2018]. http://www.cedib.org/wp-content/uploads/2013/05/Resumen_FIDH_TIPNIS_final1.pdf

Fifer, V. 1990. Los constructores de imperios: historia del auge de la goma en Bolivia y la formación de la Casa Suarez. Historia y Cultura 18: 111-141.

Frederiksen, T. and M. Himley. 2019. Tactics of dispossession: access, power, and subjectivity at the extractive frontier. Transactions of the Institute of British Geographers 45: 50-64.

Fundación Solón. 2017. Exportar y morir, Tunupa Boletin 100 [accessed January 5 2018]. https://funsolon.files.wordpress.com/2017/04/tunupa-100.pdf

Fundación Tierra. 2010. Territorios indígena originario campesinos en Bolivia entre la Loma Santa y la Pachamama. La Paz: Fundación Tierra.

García Linera, Á. 2012. Geopolítica de la Amazonía. Poder hacendal-patrimonial y acumulación capitalista. La Paz: Vicepresidencia del Estado Plurinacional - Presidencia de la Asamblea Legislativa Plurinacional.

Gobierno de Bolivia 2011. Ley 180 de protección al TIPNIS [accessed January 7 2018]. https://www.lexivox.org/norms/BO-L-180.xhtml

Gobierno de Bolivia. 2017. Ley de protección, desarrollo integral y sustentable del territorio Indígena y Parque Nacional Isiboro Secure - TIPNIS (13 Aug. 2017) [accessed January 7 2018]. http://www.derechoteca.com/gacetabolivia/ley-no-969-del-13-de-agosto-de-2017/

Gotkowitz, L. 2012. La revolución antes de la revolución. Bolivia: PLURAL.

Gudynas, E. 2012. Estado compensador y nuevos extractivismos: Las ambivalencias del progresismo sudamericano. Nueva Sociedad 237: 128-146.

Gudynas, E. 2013. Extracciones, extractivismos y extrahecciones. Un marco conceptual sobre la apropiación de recursos naturales. CLAES - Observatorio del Desarrollo 18: 1-18.

Gudynas, E. 2018. Extractivisms: tendencies and consequences. In Wise, R. D. and R. Munck. Reframing Latin American development. London: Routledge. Pp. 61-76.

Gutiérrez Aguilar, R. 2008. Los ritmos del Pachakuti. Movilización y levantamiento popular-indígena en Bolivia (2000-2005). Buenos Aires: Tinta Limón.

Himley, M. 2013. Regularizing extraction in Andean Peru: mining and social mobilization in an age of corporate social responsibility. Antipode 45(2): 394-416.

Jemio, M. 2015. El Bala, el alto costo socioambiental de la energía [accessed January 6 2018]. https://miriamjemio.atavist.com/el-bala-el-alto-costo-socioambiental-de-la-energa

Jiménez, G. 2015. Geografía del extractivismo en Bolivia. Territorios en sacrificio. Petropress 35: 4-21.

La Patria. 2016. Proyecto El Bala ya generó división en indígenas del Norte de La Paz (17 Nov. 2016) [accessed January 6 2018]. http://lapatriaenlinea.com/?t=proyecto-el-bala-ya-genera-divisia-n-en-inda-genas-delnorte-de-la-paz\&nota=274009

La Razón. 2011. Marcha del Conisur recibe apoyo y alista ley para vía por el TIPNIS (31 Dec. 2011) [accessed $\begin{array}{lll}\text { January } & 6 & 2018] . \quad \text { http://www.la-razon.com/nacional/Marcha-Conisur-recibe-alista- }\end{array}$ TIPNIS_0_1532846718.html

La Razón. 2012. Presidente crea regimiento ecológico "Juan Maraza" en el Tipnis (29 Aug. 2012) [accessed January 6 2018]. http://www.la-razon.com/nacional/seguridad_nacional/Presidente-regimiento-JuanMarzana-TIPNIS_0_1678032256.html

La Razón. 2017a. Gobierno toma contacto con indígenas y alista socialización de 5 meses sobre El Bala (31 Jan. 2017) [accessed January 6 2018]. http://www.la-razon.com/economia/Gobierno-indigenassocializacion-El_Bala-Chepete-hidroelectrica_0_2647535238.html 
La Razón. 2017b. Colonos del Conisur bloquean e impiden que comisión legislativa verifique obras en el TIPNIS (9 Aug. 2017) [accessed January 6 2018] http://www.la-razon.com/nacional/Colonos-Conisurlegislativa-verificar-TIPNIS-Bolivia_0_2761523867.html

López, C. y Tórrez, P. 2018. Tariquía de pie: una lucha campesina en Bolivia frente al extractivismo petrolero [accessed January 7 2018]. http://zur.org.uy/content/tariquía-de-pie-una-lucha-campesina-en-boliviafrente-al-extractivismo-petrolero

Moreano, M. 2019. Geografía marxista y materialismo histórico geográfico: más allá de la acumulación por desposesión. In Colectivo Geografía Crítica Ecuador (ed.). Geografía crítica para detener el despojo de los territorios. Quito: Abya Yala.

Navarro, M.L. 2014. Luchas por lo común contra el renovado cercamiento de bienes naturales en México. Bajo el Volcán 13 (21): 161-169.

Naylor, L., M. Daigle, S. Zaragocin, M.M. Ramírez and M. Gilmartin. 2018. Interventions: bringing the decolonial to political geography. Political Geography 66: 199-209.

OIT (Organización Internacional del Trabajo). 1989. Convenio No. 169 sobre pueblos indígenas y tribales en países independientes. Lima: OIT, Oficina Regional para América Latina y el Caribe.

Oxígeno. 2017. Campesinos divididos por exploración en Tariquía (26 June 2017) [accessed January 72018 ]. https://oxigeno.bo/política/21721

Página Siete. 2015. El proyecto hidroeléctrico de El Bala es un proyecto planteado en 1950 (17 July 2015). [accessed January 7 2018]. http://www.paginasiete.bo/economia/2015/7/17/proyecto-hidroelectricobala-proyecto-planteado-1950-63505.html

Página Siete. 2017a. Campesinos en emergencia advierten con desalojar a Bolpegas de Tariquía (17 Aug. 2017) [accessed January 7 2018]. http://www.paginasiete.bo/economia/2017/8/17/campesinos-emergenciaadvierten-desalojar-bolpegas-tariquia-148702.html

Página Siete. 2017b. CPILAP suscribe acuerdo con Ende para impulsar El Bala (12 Aug. 2017) [accessed January 7 2018] http://www.paginasiete.bo/nacional/2017/8/12/cpilap-suscribe-acuerdo-ende- PAGINA SIETE para-impulsar-bala-148061.html

Página Siete. 2017c. Los cocaleros imponen la ley del miedo y la zozobra en el TIPNIS (22 Aug. 2017) [accessed January 7 2018]. http://www.paginasiete.bo/nacional/2017/8/22/cocaleros-imponen-miedozozobra-tipnis-149207.html

Página Siete. 2017d. Marcha en defensa de la reserva de Tariquía se acerca a Tarija (25 April 2017) [accessed January 7 2018]. http://www.paginasiete.bo/sociedad/2017/4/25/marcha-defensa-reserva-tariquiaacerca-tarija-135563.html

Página Siete. 2018a. El Gobierno suspende inversión para exploración hidrocarburífera en reserva Tariquía (4 May 2018) [accessed January 7 2018]. http://www.paginasiete.bo/economia/2018/5/4/el-gobiernosuspende-inversion-para-exploracion-hidrocarburifera-en-reserva-tariquia-178887.html

Página Siete. 2018b. Aprueban ley para exploración petrolera en reserva de Tariquía (29 March 2018) [accessed January 7 2018]. http://www.paginasiete.bo/nacional/2018/3/29/aprueban-ley-para-exploracionpetrolera-en-reserva-de-tariquia-174787.html

Perreault, T. 2013. Dispossession by accumulation? Mining, water and the nature of enclosure on the Bolivian Altiplano. Antipode 45(5): 1050-1069.

Perreault, T. 2015. Performing participation: mining, power, and the limits of public consultation in Bolivia. The Journal of Latin American and Caribbean Anthropology 20(3): 433-451.

Platt, T., Th. Bouysse and O. Harris. 2006. Qara qara-Charka. Mallku, Inka y Rey en la provincia de Charcas (siglos $X V$ - $X V I I)$. Bolivia: IFEA-PLURAL.

Postero, N. G. 2009. Ahora somos ciudadanos. La Paz: Muela del Diablo.

Quiroga, M. 2018. Tariquía recuerda un año de la marcha en defensa de la Reserva y se mantiene firme en $\begin{array}{llllllll}\text { contra de la exploración (26 April 2018) [accessed January } 6 & \text { 2018]. }\end{array}$ 
http://andaluztarija.com/2018/04/26/tariquia-recuerda-un-ano-de-la-marcha-en-defensa-de-la-reservay-se-mantiene-firme-en-contra-de-la-exploracion/

Radcliffe, S.A. and I.M. Radhuber. 2020. The political geographies of D/decolonization: variegation and decolonial challenges of/in geography. Political Geography 78: 102-128.

Radhuber, I. 2010. Rediseñando el estado: un análisis a partir de la política hidrocarburífera en Bolivia. Umbrales (Revista del Posgrado en Ciencias del Desarrollo, CIDES-UMSA, La Paz) 20: 105-127.

Rivera Cusicanqui, S. 1984. Oprimidos pero no vencidos. La Paz: HISBOL.

Roux, R. 2015. Marx y la cuestión del despojo. Claves teóricas para iluminar un cambio de época. In Gilly, A. and R. Roux (eds.). El tiempo del despojo. Siete ensayos sobre un cambio de época. Tláhuac, México: Ítaca.

Schavelzon, S. 2012. La Asamblea Constituyente de Bolivia: etnografía del nacimiento de un estado plurinacional. La Paz: PLURAL.

Schilling-Vacaflor, A. 2017. 'If the company belongs to you, how can you be against it?' Limiting participation and taming dissent in neo-extractivist Bolivia. The Journal of Peasant Studies 44(3): 658-676.

Svampa, M. 2019. Neo-extractivism in Latin America. Socio-environmental conflicts, the territorial turn, and new political narratives. Cambridge: Cambridge University Press.

Tapia, L. 2014. La sustitución del pueblo. La Paz: Autodeterminación.

Tapia, L. 2016. El momento constitutivo del estado moderno capitalista en Bolivia. La Paz: Cides Umsa.

Territorios en Resistencia. 2017. Caciques del MAS someten y empobrecen a indígenas del norte del Tipnis (16 April 2017) [accessed January 7 2018]. https://www.territoriosenresistencia.org/noticias/caciques-delmas-someten-y-empobrecen-a-indigenas-del-norte-del-tipnis

Torres, N. 2019. Minería en el territorio de Kimsakocha: cercamiento, desposesiones y el rol del Estado. In Colectivo Geografía Crítica Ecuador (eds.). Geografía crítica para detener el despojo de los territorios. Quito: Abya Yala.

Valenzuela-Fuentes, K. 2019. Militant ethnography and autonomous politics in Latin America. Qualitative Research 19(6): 718-734.

Vallejo, I., G. Zamora and W. Sacher. 2019. Despojo(s), segregación social del espacio y territorios de resistencia en América Latina. Presentación del dossier. Íconos, Revista de Ciencias Sociales 64: 11-32. 